\title{
The New Informational Paradigm: Developing Practice-Led Approaches to the use of Mobile ICT in Social Work
}

Dr. Steven Baker, Microsoft Research Centre for Social Natural User Interfaces, University of Melbourne, Melbourne, Victoria, Australia, 3010. steven.baker@unimelb.edu.au

Professor Jeni Warburton, John Richards Initiative, La Trobe University, Wodonga, Victoria, Australia. P.O. Box 821, Wodonga, Victoria, Australia 3689. j.warburton@latrobe.edu.au

Dr. Suzanne Hodgkin, La Trobe Rural Health School, La Trobe University, Albury/Wodonga. Po Box 821, Wodonga, Victoria, Australia.s.hodgkin@latrobe.edu.au

Dr. Jan Pascal, School of Social Science and Public Policy, Keele University, Staffordshire, United Kingdom, ST5 5BG. j.pascal@keele.ac.uk 


\begin{abstract}
Information and Communication Technology (ICT) has profound impacts on society as people integrate technology into their lives. Social work is similarly influenced by ICT as workplaces, individual practitioners and clients adopt new forms of technology and this has prompted an increasing focus of on the implications of technology on all aspects of professional practice. Drawing on the work of Spanish sociologist Manuel Castells as its theoretical foundation, this article reports on a Participatory Action Research (PAR) project that sought to understand the potential practice-led integration of ICTs with traditional social work practice at an organisation in rural Victoria, Australia. Eight participants were provided with tablet computers and collaborated with the researcher over a period of eight months to trial ways in which ICTs might complement traditional face-to-face practice in the field. Findings highlight a range of benefits and challenges in adopting a practice-led approach that spaned three key themes; successful practice-led approaches, technological friction, and challenges inherent in what Castells describes as the transition to network enterprises. Findings highlight the need for ongoing research and engagement to ensure that technological advances are implemented in ways that are consistent with the enduring ethics and philosophies of the social work profession.
\end{abstract}




\section{Introduction}

As new forms of Information and Communications Technology (ICT) become ever more ubiquitous, professions such as social work are increasingly questioning how these new tools impact on practice (Baker et al., 2014; Cooner, 2014; Mishna et al., 2012; Schembri, 2008). Broader cultural changes form the backdrop as access to these new technological tools impact on the way we live and work (Castells, 1996). We have argued previously that social workers need to adopt a practice-led approach to the use of ICTs, so as to ensure that they might be used in ways that benefit, rather than detract from the enduring values of the profession (Baker et al., 2014). However, the question arises as to how social workers will adopt a practice-led approach to ICT use, and what organisational and technological challenges will need to be addressed to support a practice-led approach.

In this paper, we explore these issues and report on a Participatory Action Research (PAR) project, which was conducted with social work professionals at a homelessness support agency in regional Victoria, Australia. We address the research questions; "how might mobile ICTs be integrated into existing face-to-face social work practice?" and "what are the advantages and challenges identified by social work practitioners"? In doing so, we draw on the theoretical foundation provided by Manuel Castells in his theory of the network society. We begin by briefly outlining Castells' notion of a new informational paradigm, and the implications of this for social work practice. 


\section{The Network Society}

The theoretical foundation for the study was Spanish sociologist Manuel Castells' theory of the network society (Castells, 2010, 2011a, 2011b). Castells contends that society is now in the midst of a transition to a new structure based largely on access to ICTs and new forms of social organisation based around networks. He refers to this new society as the Network Society (Castells, 2011b). From a structural perspective, Castells asserts that we have transitioned to a new informational paradigm in which ICTs are playing a vital role (Castells, 2000). In this new paradigm, it is not technology itself that is changing society, but rather society is changing and adapting in response to the new technological revolution, just as society adapted to the new technologies of the Industrial Revolution that preceded it (Castells, 2000, 2011b).

Understandably, social workers, like the rest of society, are facing new challenges in adapting to this rapidly changing world. There is strong evidence that many social workers are struggling with the implications of technology on their practice (Baker et al., 2014; Parton, 2006; West \& Heath, 2011). In light of these concerns, the question arises as to how the profession might process these changes and adapt to the advantages of the new technological tools of the information age, while still holding true to the basic human foundations of social work practice. Based on our findings, we posit that Castells' conceptualisation of the new Informational Paradigm, what some have termed "soft 
technological determinism", offers a framework within which exciting new forms of social work practice might emerge (Stalder, 2006, p. 32). This is the basic premise behind what Hill and Shaw (2011), have termed a practice-led, rather than technology-led approach to the use of ICT in social work.

\section{Technology-led and Practice-led Approaches to ICT use in Social Work}

The technology-led approach sees social work practice as being understood and evaluated as a secondary consideration to those of ICT developers, managers and funding bodies (Hill \& Shaw, 2011). This approach, in Castellsian terms, is most akin to technological determinism and casts social workers as passive and powerless in the face of technological change. This approach lays at the heart of many of the criticisms of ICT use in social work. These include its alignment with managerialism (Burton \& van den Broek, 2009; Gillingham, 2014, 2015; Hill \& Shaw, 2011; Watling \& Rogers, 2012; West \& Heath, 2011); the associated issues of lack of craft and narrative richness (Hill \& Shaw, 2011; Parton, 2006; Sapey, 1997; Watling \& Rogers, 2012) and the perception of ICT as a management, rather than a social work tool (Burton \& van den Broek, 2009; Hill \& Shaw, 2011; Parrott \& Madoc-Jones, 2008). Practice-led approaches, in contrast, involve "starting with social work practice, not with the ICTs themselves" (Hill \& Shaw, 2011, p. 11). This approach sits comfortably with Castells' new technological paradigm in which technology influences and shapes practice in new ways in response to the users needs. When looked at from this perspective, social workers have a key role to play, 
alongside other stakeholders, in the development of ICT infrastructure (Baker et al., 2014).

There remains, however, a clear gap in the literature relating to what these new approaches to practice might look like and what challenges a practice-led approach might bring to social workers in the field. It is this gap in the research literature that the study sought to address.

\section{Research Design}

The research reported here is part of a larger action research project, which sought to better understand how ICT can be used by disadvantaged clients, and be integrated into social work practice, within a homelessness support agency in Bendigo, a regional centre located in central Victoria, Australia. The research involved two separate Participatory Action Research (PAR) stages run concurrently across two sets of participants, the clients and the workers. One stage of the research examined the use of tablet computers by elderly clients of the service with histories of homelessness, social isolation and complex needs (Baker et al., 2016). The second stage, the focus of the current paper, concentrates on how social workers use ICT in support of their daily face-to-face practice. Thus, the research questions being addressed here are "how can mobile ICTs be integrated better into social work practice?" and "what are the advantages and challenges identified by social work practitioners"?

PAR was chosen as the research methodology for the project. The overarching goal of PAR is to partner with participants in the 
research and to combine theory and practice in the service of social change. These goals were consistent with the overall aims of the project (Grant et al., 2008). PAR, in accordance with all variants of action research, incorporates cycles of planning, action and reflection throughout all of the phases of the research (Reason \& Bradbury, 2008). This iterative research process, combined with its focus on individual flourishing, emancipation and facilitating change, has led to action research variants becoming increasingly popular for examining the impact of ICT in organisations and with vulnerable populations (Alston \& Bowles, 2003; Hearn et al., 2009; Reason \& Bradbury, 2008).

\section{Methods}

The study received ethical approval from La Trobe University's Human Ethics Committee (FHEC14/027). The participants were all members of the homelessness support agency's Assertive Outreach (AO) team. This program provides long-term case management and support services for people living independently in the community with histories of homelessness, social isolation and complex needs, a catch all phrase that encompasses substance abuse, physical and mental health issues.

The AO team were identified as being especially suited to the research goals for three primary reasons. First, the nature of the work provided a good mix of practice contexts from which to test practice-led approaches to mobile ICT use. Second, the service is funded to provide long- term support, this enabled continuity and stability for both workers and clients, an issue identified as 
critical in other ICT-based research with disadvantaged groups (Waycott et al., 2012, 2013, 2015). Finally, the first author had previous practice experience in the AO team and was therefore familiar with the organisational culture and regulatory environment. This final point highlights the emic nature of the research, and its alignment with PAR's focus on the researcher being actively engaged in the research process (Reason \& Bradbury, 2008) .

Eight workers expressed interest in participating in the project. Six of the participants held undergraduate degrees in social work, the remaining two having qualifications in welfare and disability care. This mix of social workers and welfare workers is common in Australian practice settings (McDonald et al., 2003; Mendes, 2005). Seven of the eight participants were based in the organisations central office in Bendigo and one worker was based in Echuca, approximately 90 kilometres from Bendigo. All are identified here using pseudonyms to protect their identities.

Data collection occurred between May and December 2014. The relatively long data collection period was important for facilitating collaboration and building an environment of trust and open communication essential for PAR (Reason \& Bradbury, 2008; Swantz et al., 2008). During this time, the lead author was based at the homelessness agency three to four days each week to enable him to collaborate with the participants in developing the project. In addition to the research tasks being coordinated and completed during this time, the lead author was able to 
participate in regular staff meetings and attend client visits with the participants. This commitment to engaging in the everyday workplace culture of the participants helped to build rapport and also provided opportunities to identify situations where a practice-led approach to ICT use might be applied.

PAR draws on a broad range of research methods. This triangulated approach, incorporating multiple sources of data and multiple methods of data collection, allows PAR researchers to obtain richer and more rigorous research data (Craig, 2009; Dick, 1999; Lennie, 2006). Data collection methods adopted for the research project included a survey, ICT training sessions, focus groups, individual semi-structured interviews.

In accordance with the participatory nature of PAR, participants were involved in the design and development of many aspects of the project, which then proceeded through three primary research phases. The first phase involved a number of information, goal setting and training sessions aimed at collecting baseline data, establishing an initial focus for the project and ensuring that the participants' tablet computers were correctly configured. Tablets chosen for the research project were cellular network connected Apple iPads. Another key aspect of this phase of the research involved spending time with the participants, both in the central office and during outreach visits, to observe common tasks and identify areas in which access to the tablet might aid practice. Further, a brief survey, adapted from an earlier research project examining the use of ICT in rural areas (Feist et al., 2012), was also administered during the first phase. The 
intent of the survey was to establish a baseline of data relating to the participants' familiarity with, and use of, a range of technologies.

During the second phase, participants collaborated with the researcher to trial a range of practice-led approaches, identified and developed during the initial phase. Approaches spanned three key areas of social work practice; initial assessment, counselling and case management and administrative duties. Towards the end of the second phase, a range of semi-structured focus groups and face-to-face interviews were conducted to reflect on the successes and challenges identified and to consider new approaches and goals for the final phase of data collection.

Following reflection on the previous phases, the final phase involved fine-tuning the practice-led techniques that were trialled during the second phase. Following participant feedback, new techniques were also trialled as participants' confidence and experience with the devices increased. Towards the end of this phase, a final round of focus groups and face-to-face interviews were conducted. In addition to gathering data on the final phase, there was a focus on how participants might continue to utilise mobile ICT when the study concluded and what extra supports might be required to facilitate practice-led approaches into the future. This was critical to build sustainable outcomes for workers and the agency, but also for the clients reliant on the support of their workers. An overview of the methods adopted in the three research phases are summarised in Table 1. 
Throughout the data collection period, data were transcribed where necessary and imported into NVivo 10 Data Analysis software for coding and analysis. In addition to the data being subjected to both inductive and deductive coding by the lead author, a number of additional consistency checks were completed to improve trustworthiness (Thomas, 2006). Rigour was achieved in two ways. First, through independent parallel coding by all authors to ensure consistency between codes. Second, stakeholder checks were undertaken, involving discussion of findings with participants to ensure emergent themes aligned with their personal experiences during the project.

Table 1 Methods adopted during research phases

Phase of study and approximate duration

Methods adopted

\begin{tabular}{|c|c|}
\hline $\begin{array}{l}\text { First phase (approximately } 8 \\
\text { weeks) }\end{array}$ & $\begin{array}{l}\text { - Setting initial goals for the project } \\
\text { - Identify initial practice-led approaches } \\
\text { - } \text { Configuring tablet computers } \\
\text { - ICT Training Sessions } \\
\text { - Observation of participants existing work practices } \\
\text { - Survey of participants experience with ICTs }\end{array}$ \\
\hline $\begin{array}{l}\text { Second phase (approximately } \\
12 \text { weeks) }\end{array}$ & $\begin{array}{l}\text { - Implement initial practice-led approaches across three } \\
\text { areas of practice } \\
\text { 1. Assessment } \\
\text { 2. Counselling and Case Management } \\
\text { 3. Administrative tasks } \\
\text { - Semi-structured face-to-face and group interviews } \\
\text { - Revise practice-led goals for third (final) phase }\end{array}$ \\
\hline $\begin{array}{l}\text { Third phase (approximately } 12 \\
\text { weeks) }\end{array}$ & $\begin{array}{l}\text { - Implement revised practice-led approaches } \\
\text { - Implement new practice-led techniques identified during } \\
\text { - Second phase } \\
\text { - Semi-structured face-to-face and group interviews } \\
\text { of the study }\end{array}$ \\
\hline
\end{tabular}




\section{Findings}

Analysis of the multiple levels of data identified three key themes that emerged in response to the research questions. In summary, these comprised, first, a number of successful practiceled approaches that workers felt improved their practice experiences and benefited clients. Second, a range of challenges in relation to workers trying to incorporate mobile ICT into their practice, grouped under the theme of technological friction. Solutions to some of these problems were subsequently negotiated through the participatory process. The third key theme related to some thorny challenges faced by social workers in relation to mobile ICT use, particularly as organisations increasingly transition to what Castells describes as networked enterprises (Castells, 2011b). These include concerns about privacy and confidentiality, and the blurring of work and personal time. Each of these key themes will now be discussed in more detail.

\section{Successful Practice-Led Approaches}

During the data collection period, participants used their tablets in all areas of practice in the field, including initial assessment, taking case notes and completing case management tasks, as well as completing administrative functions.

\section{Assessment}

During initial assessment, and at various times throughout their work with clients, social workers are required to complete a range of assessment related paperwork, including gathering base 
line data about the client, completing assessment tools and housing applications, developing case plans, signing various consent forms, and completing legal documents. Traditionally, all these assessment documents required printing prior to the client visit and were then filled out by hand. Completed documents were then stored in filing cabinets. After adopting a practice-led approach, participants were able to undertake these tasks on their tablets and this offered several advantages.

A clear advantage was accessibility to all forms for every visit. It is not unusual for a worker to overlook or not have the required document and only realise this once they have travelled to the client's home. As Fiona commented, "we're an outreach program. It's so much easier to be able to go out and get things for people straight away, like a housing application, rather than having to go back [to the office]. You might not be able to go and see [the client] again for three days". Waiting for the next visit causes delays for clients in accessing vital services. Further, participants were able to capture signatures using the tablets touch-screen interface and use the tablets camera to document client information such as driver's licences, outstanding bills or health care cards. All this information was either emailed or saved to a cloud storage application, such as Google Drive, so that they were available at their desktop computer once they returned to the office. This information was then saved to the agency's Client Management System (CMS). Reflecting on this streamlined process, Natalie said "The accessibility to things - 
the documents, the internet, work based stuff... is I think really helpful. It cuts time [and] time is money".

The ability to collect signatures electronically during assessment presented clear advantages, particularly when working with remote clients. Using a practice-led approach, participants collectively discussed, and then devised, a new assessment procedure that allowed them to capture a signature so that it could be used at a later time after gaining, and documenting, permission from the client. This process alone offered the potential to reduce waiting times for clients to be linked with key services and receive vital support, such as access to public housing, more quickly.

Finally, easy access to a camera was a particular advantage in some situations. For example, Quinn, a social worker who was working in a specialised program with particularly complex clients, was concerned about a skin lesion that she could see on an elderly client when she was conducting an assessment. The client was reluctant to seek help and was not able to see the affected area. Quinn was able to photograph the lesion and show the client and, as a result, was able to convince the client of the need to seek medical assistance. Participants also reported using the tablet's camera to document where their clients lived. This included documenting an area where a client was 'sleeping rough' so that other workers and services would be better able to locate them.

These findings underscore two central aspects of Castells' theory of the network society. Providing the participants with 
electronic access to their practice documents at all times allowed them to take control of their interactions with clients in innovative ways, reducing the time necessary to deliver services and freeing the workers to improvise creative solutions to problems using their tablets. These are examples of what Castells refers to as counterpower, mastering the key means of socialised communication, ICT, to empower and support otherwise marginalised groups (Castells, 2009; Castells, 2012). The participants leveraging of multiple types of media such as text and photographs similarly illustrates the way that ICTs are transforming culture via the incorporation of "written, oral, and audio-visual modalities of human communication" into what Castells refers to as the culture of real virtuality (Castells, 1996, p.328). Practiceled approaches to ICT use such as these also begin to restore a sense of craft and creativity back to social workers in the field, counteracting the historically technology-led approach to ICT use that was characterised by a loss of richness and craft (Hill \& Shaw, 2011; Parton, 2006; Watling \& Rogers, 2012).

\section{Case Notes and Case Management}

Participants were able to trial different ways of capturing case notes using the tablet including techniques such as typing the notes while talking with the client, using a stylus to 'hand write' case notes and recording discussions with a client and transcribing them at a later time. Participants felt that a range of input techniques were necessary depending on the individual client's circumstances. In general, typing the case notes while 
talking with the client seemed the most accepted form. The stylus proved too slow for taking notes, however, several participants expressed the desire to be able to do this into the future as the technology improves. Reflecting these different approaches, Ida noted: "One of my clients... it just suits him because he likes to recline on the couch and... I sit up the other end of the room and he just talks. He's very comfortable with me [typing] on the iPad. Then I have other clients that would find it rude [as they] want that eye contact".

While time can be saved through direct input into the tablet, workers also noted that using the tablet while sitting with the client made the work they were doing much more visible and reassured the client that progress was being made. As Quinn noted; "I'm showing them what's happening and that I'm sending an email and things like that, I think hopefully it includes them in the process in some way, or shows them that this whole world is happening". This finding also highlights the potential for social workers to use practice-led approaches to ICT to build capacity and exercise counterpower (Castells, 2012; Smith, 2013).

The tablet proved to be very useful for a range of common case management tasks. Several participants commented on the ability to make appointments with doctors and schedule diary reminders on the tablet while sitting with the client. This replaced the need for multiple phone calls and scheduling when back at the office. Quinn detailed a particular example where the tablet was useful during an aged care facility visit with an elderly man who had hearing loss and dementia. 


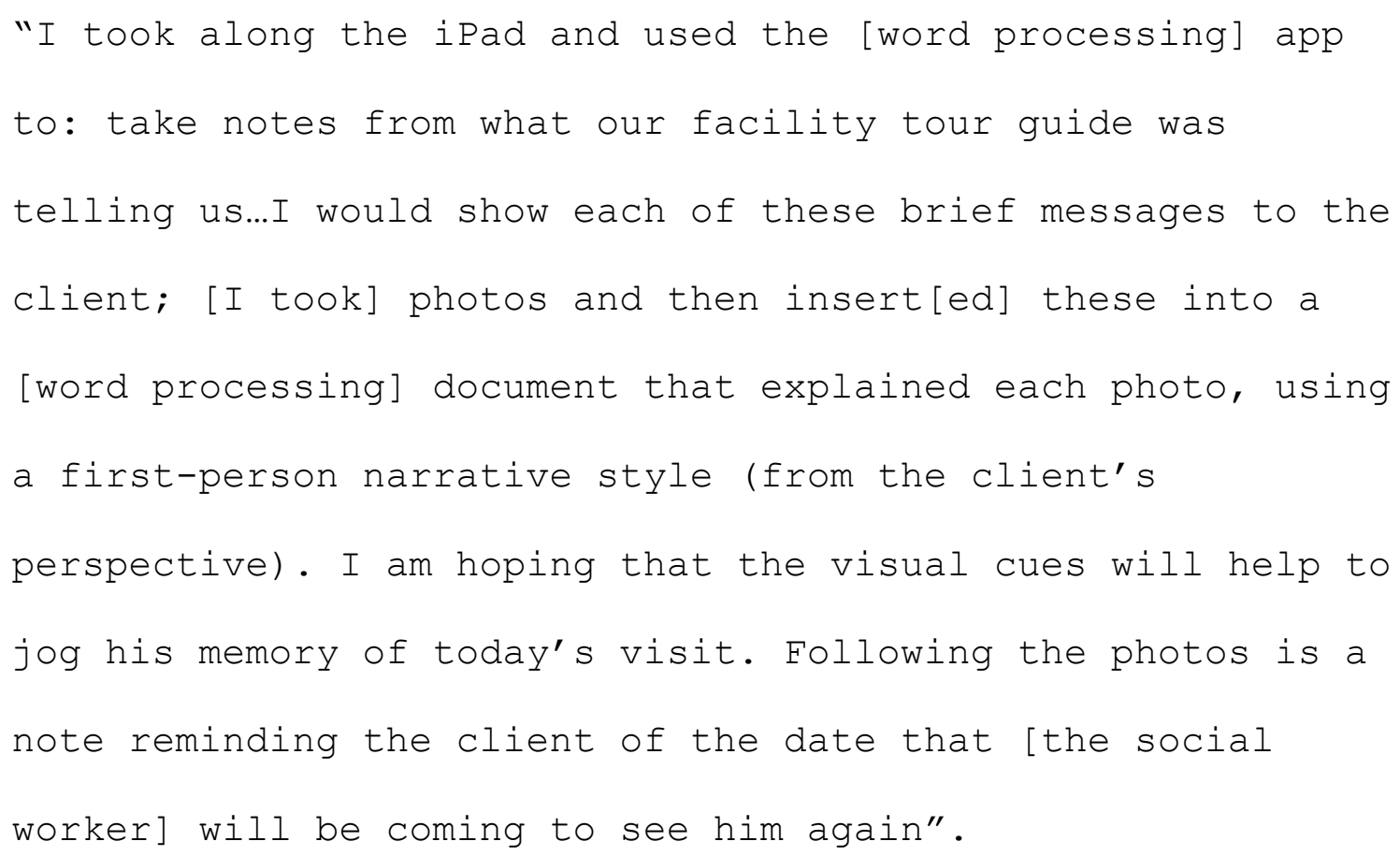

\section{Administrative Tasks}

A final clear advantage relates to the ability for tablets to reduce administrative time when back at the office. In addition to the time saving tasks noted above, participants detailed other ways in which having access to mobile ICT reduced their administrative burden. For example, during the data collection phase, workers used their tablet to book cars while in the field, and submitted an electronic version of the travel documentation. Although a seemingly small change, this process saved the workers considerable time and meant that upcoming appointments could be confirmed while visiting the client. Considering research has indicated much of a social workers time is spent attending to administrative tasks (Baginsky et al., 2010), reductions in time spent on administrative tasks can lead to significant productivity gains and increased client contact.

\section{Technological Friction}


Despite these successes, findings from the project also identified some technological barriers that hampered the effectiveness of the devices. In particular, given that face-toface social work with vulnerable populations is dependent on fast, attentive and open forms of communication, any technological friction that disrupts this relationship has a negative effect on building rapport and trust, hampering an effective response.

\section{Software Issues}

Several attempts at developing electronic documentation that would encourage a paperless workflow were hampered by software issues. In the initial phases of data collection, all of the AO teams practice documents, which were in either Microsoft Word or Excel format, were uploaded to Evernote, a cloud based note taking app, so that participants could, in theory, access and complete all documents from their tablets. Completed documents should then be instantly available on the worker's desktop computer using the companion desktop version of Evernote. However, this system exposed multiple problems. First, despite conducting specific training on the use of Evernote, participants did not enjoy using the application. Participants were confused by the app's interface. When discussing this failed experiment, participants expressed views such as; "I have tried to use it - I do find it a little bit hard to navigate... I don't know if I am in personal or public?" (Natalie), "...it's just not something that I think to use" (Bronwyn), "I would like to get the documents off Evernote to do it, but I'm not 100 per cent sure how to edit them..." (Fiona). 
Participants instead preferred to use software with which they were familiar, even if these solutions required additional copying and pasting in order to add the data to the CMS. This finding is supported by previous social work studies that have highlighted the challenges of integrating technological advances into existing client management and reporting systems (Stillman \& McGrath, 2008) .

A second issue involved transferring data into Word and Excel using the tablets' touch-screen interface. Although adding data to the documents was possible, workers noted that it was not user friendly and was too slow when trying to work with a client. As a result, they simply got frustrated with this input method and initially reverted to printed documents. These issues highlight the importance of usability, a topic of intense interest in the field of human-computer interaction (Issa \& Isaias, 2015).

A final issue involved transferring data between the iPad's applications and the CMS. The CMS had been configured to accept small amounts of text directly typed into its database, however, as participants began to transfer larger files that contained text and photographs, the CMS rejected the files due to them exceeding its file size limit. The organisations I.T. staff refused to increase this limit, forcing participants to export files through multiple applications that compressed the data down to 'acceptable' levels. This initially negated any advantages that the paperless workflow offered.

A benefit of the participatory design of the study was that these issues were able to be addressed as the research progressed. 
Later iterations of the paperless workflow used documents that converted to editable PDF format with touch-screen friendly conventions such as drop down dialogue boxes and buttons. This allowed the participants to add data quickly while conversing with clients. Completed PDFs were subjected to a streamlined compression process that made them suitable for upload to the CMS. Evernote was abandoned in favour of documents being stored in more straightforward cloud storage in Google Drive. This gave the participants easy access to all their paperwork without having to learn a complicated User Interface (UI) .

\section{Hardware Friction}

The tablet hardware used in the research project also created issues in relation to technological friction. Prior to the beginning of the research project, the homelessness organisation had purchased tablets for the participants to use. Unfortunately, in an attempt to contain costs, the decision was made to purchase older model ipads. This introduced a range of technological issues and highlighted the need for fast hardware when using mobile ICT in the types of dynamic environments facing social workers in the field. A finding that highlights this issue related to the slowing of app launching and closing because of the ageing specifications of the device. While small delays may not have been an issue for personal use, when trying to accomplish tasks while interacting with a client, such delays seriously hampered engagement as workers tried to shift their attention between client and technology. 
This issue became more pronounced later in the project when a new version of the iPads system software was released and existing apps became even less responsive. The older hardware also limited the usability of the camera in low light environments and when macro focusing. As a result, the participants' attempts to use the camera to 'scan' client documents indoors were frequently out of focus or pixelated, which reduced their effectiveness.

\section{Challenges of the Networked Enterprise}

A final theme emerging from the data related to a clutch of issues faced by the participants when attempting to use their tablets within the constraints of a corporate environment which was struggling to adapt to rapid technological change. These issues were collectively grouped under the heading of adapting to the challenges of the network enterprise, a term borrowed from Castells (Castells, 1996).

\section{Privacy and Confidentiality}

As participants increasingly integrated their tablets into their practice, a range of privacy and confidentiality issues arose that demanded the development of new approaches and policies. When the participants began to configure their tablets prior to beginning the research project, many chose to set up the device with both personal and professional logins for a range of services such as e-mail and instant messaging. This desire to mix the personal and professional, is an understandable consequence of using a device, such as an iPad, that has its origins in personal, 
rather than enterprise, computing. However, the risk that the participants might unwittingly send personal information to their clients was identified as an issue for several participants. Laura recounted one such instance, "I did make that mistake one time. I sent a... I was with a client and it [the tablet] must have been on my Yahoo and sent an e-mail. But it ended up being sent from my personal e-mail. I really didn't like that at all".

When exploring the use of the tablet for assessment, workers were concerned that there were no guidelines or assessment questions that set expectations about respecting both the clients' and the social workers' online privacy. As a result, the group developed a simple question to address this, and inserted it into the initial assessment questionnaire to prompt a conversation about online confidentiality. Finally, given the rural practice setting and the proliferation of social networks and online services, such as dating apps, that each provide potential vectors for privacy and confidentiality breaches, participants felt that much more attention needed to be given, at the organisational level, to protecting staff and clients' online lives. These findings highlight the need for ongoing attention to be payed to issues of privacy and confidentiality within the social work profession and the development of new guidelines to assist social workers to adapt to these ongoing challenges (Chenoweth \& McAuliffe, 2015; Reamer, 2013). 


\section{'Work Time’ versus 'Personal Time’}

Findings illustrated the increased blurring of the distinction between 'work' and 'personal' time, Castells refers to this blurring as a key challenge facing workers in networked enterprises (Castells, 1996). All participants reported using their iPads to continue doing work outside of work hours, while not being reimbursed for this work. Participants, however, drew a clear distinction between their willingness to do administrative tasks, such as case notes and e-mails outside work hours and responding to client enquiries using the device. Laura neatly summarised this distinction; "I'll do administrative stuff out of work hours on this [the iPad], but I'll never contact clients... administrative things like checking e-mails and things like that, I do that, I do that quite a bit... but yeah, I won't do client stuff out of hours". Part-time staff, in particular, expressed positive feelings about the ability to continue to work while at home and felt that this allowed them to clear the administrative burden, rather than sort through the backlog of e-mail or case notes when next in the office. Interestingly, although all participants acknowledged that they were increasingly doing unpaid work from home using the tablet, only one participant (Natalie), expressed the need for organisations to develop clear guidelines regarding out of hours work and remuneration.

\section{Discussion}

Findings from the Supportive Network project demonstrate the clear potential for practice-led approaches to mobile ICT to be 
integrated into existing face-to-face social work practice. Whether conducting an initial assessment, taking case notes when with a client or more efficiently completing administrative tasks, participants felt that mobile ICT, combined with a practice-led approach to their use, improved social work practice. They were also able to identify benefits to clients from workers incorporating mobile ICT with face-to-face practice. These included the visibility of case progress and faster access to services and supports.

However, findings also suggested that for mobile ICTs to be integrated better into social work practice, three pre-conditions need to be met. Though it may seem self-evident, organisations and social workers must first be committed to using a practice-led approach. Social service organisations faced with funding constraints and the need to adhere to strict funding guidelines, can be predisposed towards conservative strategies in relation to ICT. However, results highlight clear potential for organisations to make productivity gains and increase worker and client satisfaction if the practice-led approach is adopted. Social workers too will have to embrace change if they are to fully benefit from a practice-led approach to mobile ICT use. There are additional demands placed on social workers when adopting a practice-led approach as processes are developed and refined. However, our findings indicate that the practice-led approach to technology use offers substantial benefits to social workers. These include reduced time spent on administrative duties, more 
time spent with clients in the field and the development of creative new approaches to the craft of social work.

Committing to a practice-led approach to mobile ICT backed social work practice also means committing to reducing the impacts of technological friction. Findings clearly demonstrate the deleterious effect that such friction can have on building rapport with clients in the field. Even small delays, caused by poorly chosen software or slow and outdated hardware, can cancel out the benefits of the practice-led approach. Mobile software and hardware in the field of personal computing continues to advance at a dizzying pace. For example, improvements to stylus input since this research was conducted, would seem to have largely addressed the issues that participants faced during this project. Organisations adopting a practice-led approach must therefore be committed to continuous improvement to ensure that practice-led processes continue to evolve with technological advances. The reduced cost of consumer electronics, such as tablets and smartphones, as compared to traditional enterprise hardware and software, should help to mitigate the costs of ensuring workers have up to technology. The productivity gains evident in this project should also help to defray such expenses over time. Finally, in order to realise the benefits of a practice-led approach to mobile ICT development, there is a need for I.T. departments to embrace new approaches that combine collaboration and individualised training and support. Participants in this study expressed the desire for a more consultative approach, which perhaps stems, in part, from the fundamental shift that is 
occurring as mobile forms of ICT infiltrate the workplace. In the earlier enterprise environment, dominated by desk-based PCs running software mandated by funding bodies, end users typically were not experts at using the software and consequently felt disempowered and at the mercy of confusing technology. In such an environment, I.T. staff were able to maintain control over how the technology was configured and used. As mobile forms of ICT become ubiquitous tools, used by everyone in both their private and working lives, end users are increasingly becoming experts in the use of these forms of ICT. This is breaking down the power structure of the traditional I.T. department. Instead, the I.T. department has a crucial new role to play in this new technologically democratised workplace, that of an expert peer, rather than a detached dictatorship. Participatory forms of evaluation of mobile ICT offer the potential for new collaborative approaches between social workers and I.T. staff to be realised.

\section{Conclusion}

As the culture of the network society continues to adapt and change in response to the new technologies of the internet age, social workers will continue to be challenged to find new ways to integrate technology into practice. Manuel Castells' new Informational Paradigm provides a theoretical framework for social workers to understand the challenges of new technologies, while holding firm to the core values that will continue to guide the profession. The practice-led focus and participatory design of the Supportive Network project, demonstrate one way in which social 
workers can begin to proactively meet these new challenges.

Findings demonstrate the potential for new practice approaches to be developed that preserve the art and craft of social work practice and benefit social workers, social service agencies and their clients. The findings also begin to highlight the technological challenges inherent in working in complex environments and the need for new organisational responses that minimise these issues. While these results are encouraging, the small scale and single practice setting of the project highlight the need for further studies, across a range of social work practice areas, that trial practice-led approaches. It is only through such research that the full benefits of a practice-led approach to ICT will become evident. What is clear, however, is that the time has come for social workers to engage with new technologies rather than passively adapt to technological change. The Supportive Network project demonstrates that such engagement is possible and that practice can only be enhanced when social workers are proactively involved with the development of ICTs in the field. 


\section{References}

Alston, M., \& Bowles, W. (2003). Research for social workers : an introduction to methods. Crows Nest, N.S.W., Allen \& Unwin.

Baginsky, M, Moriarty, J, Manthorpe, J, Stevens, M, MacInnes, T, \& Nagendran, T. (2010). Social workers' workload survey: messages from the frontline: findings from the 2009 survey and interviews with senior managers. Retrieved from http://dera.ioe.ac.uk/1945/

Baker, S., Warburton, J., Hodgkin, S., \& Pascal, J. (2014). Re-Imagining the Relationship Between Social Work and ICT in the Network Society. Australian Social Work. 67(4), pp. 467-478.

Baker, S., Warburton, J., Hodgkin, S., \& Pascal, J. (2016). The Supportive Network: Rural Disadvantaged Older People and ICT. Ageing \& Society, DOI 10.1017/S0144686X16000350, published 7 April, 2016.

Burton, J., \& van den Broek, D. (2009). Accountable and Countable: Information Management Systems and the Bureaucratization of Social Work. British Journal of Social Work, 39(7), pp. 1326-1342.

Castells, M. (1996). The rise of the network society. Malden, Mass., Blackwell Publishers.

Castells, M. (2000). Materials for an exploratory theory of the network society1. The British Journal of Sociology, 51(1), pp. 5-24.

Castells, M. (2009). Communication Power. Oxford, UK, Oxford University Press.

Castells, M. (2010). End of Millennium: The Information Age: Economy, Society, and Culturel (Vol. 3). Hoboken,NJ, John Wiley \& Sons.

Castells, M. (2011a). The power of identity: The information age: Economy, society, and culture (Vol. 2). Hoboken,NJ, John Wiley \& Sons.

Castells, M. (2011b). The rise of the network society: The information age: Economy, society, and culture (Kindle, Vol. 1). Wiley-Blackwell.

Castells, M. (2012). Networks of Outrage and Hope. Cambridge, UK, Polity.

Chenoweth, L., \& McAuliffe, D. (2015). The road to social work \& human service practice: an introductory text. South Melbourne, Vic., Thompson Learning.

Cooner, T. S. (2014). Using facebook to explore boundary issues for social workers in a networked society: Students' perceptions of learning. British Journal of Social Work, 44(4), pp. $1063-$ 1080 .

Craig, D. (2009). Action research essentials. San Francisco, CA, Jossey-Bass.

Dick, B. (1999). Sources of rigour in action research: addressing the issues of trustworthiness and credibility. In Association for Qualitative Research Conference "Issues of rigour in qualitative research", Melbourne, Australia.

Feist, H. R., Parker, K., \& Hugo, G. (2012). Older and Online: Enhancing social connections in Australian rural places. The Journal of Community Informatics, $\mathbf{8}(1)$. 
Gillingham, P. (2014). Technology configuring the user: implications for the redesign of electronic information systems in social work. British Journal of Social Work Advance Access published December 4, 2014, doi:10.1093/bjsw/bcu141.

Gillingham, P. (2015). Electronic information systems and human service organizations: the unanticipated consequences of organizational change. Human Service Organizations: Management, Leadership \& Governance, 39(2), pp. 88-100.

Grant, J., Nelson, G., \& Mitchell, T. (2008). 'Negotiating the challenges of participatory action research: Relationships, power, participation, change, and credibility' in Reason, P. and Bradbury, H. (eds), The SAGE Handbook of Action Research, Thousand Oaks, CA, SAGE Publications Limited.

Hearn, G. N., Tacchi, J. A., Foth, M., \& Lennie, J. (2009). Action research and new media: Concepts, methods and cases. New York, NY: Hampton Press.

Hill, A., \& Shaw, I. (2011). Social Work and ICT. Thousand Oaks, CA: SAGE Publications Limited.

Issa, T., \& Isaias, P. (2015). Sustainable Design. London, UK, Springer-Verlag London Ltd.

Lennie, J. (2006). Increasing the rigour and trustworthiness of participatory evaluations: learnings from the field. Evaluation Journal of Australasia, 6(1), pp. 27-35.

McDonald, C., Harris, J., \& Wintersteen, R. (2003). Contingent on context? Social work and the state in Australia, Britain, and the USA. British Journal of Social Work, 33(2), pp. 191-208.

Mendes, P. (2005). The history of social work in Australia: A critical literature review. Australian Social Work, 58(2), pp. 121-131.

Mishna, F., Bogo, M., Root, J., Sawyer, J.-L., \& Khoury-Kassabri, M. (2012). "It just crept in”: The Digital Age and Implications for Social Work Practice. Clinical Social Work Journal, 40, pp. 277-286.

Parrott, L., \& Madoc-Jones, I. (2008). Reclaiming Information and Communication Technologies for Empowering Social Work Practice. Journal of Social Work, 8(2), pp. 181-197.

Parton, N. (2006). Changes in the Form of Knowledge in Social Work: From the "Social" to the "Informational"? British Journal of Social Work, 38(2), pp. 253-269.

Reamer, F. (2013). Social Work in a Digital Age: Ethical and Risk Management Challenges. Social Work, 58(2), pp. 163-172.

Reason, P., \& Bradbury, H. (2008). The Sage handbook of action research : participative inquiry and practice. Thousand Oaks, Calif.: SAGE Publications.

Sapey, R. (1997). Social Work Tomorrow: Towards a Critical Understanding of Technology in Social Work. British Journal of Social Work, 27(6), pp. 803-814.

Schembri, A. M. (2008). www.why-social-workers-need-to-embrace-Web2.0.com.au. Australian Social Work, 61(2), pp. 119-123.

Smith, R. (2013). Castells, Power and Social Work. British Journal of Social Work, 43(8), pp. 
$1545-1561$.

Stalder, F. (2006). Manuel Castells. Cambridge, UK, Polity.

Stillman, L., \& McGrath, J. (2008). Is it Web 2.0 or is it Better Information and Knowledge That we Need? Australian Social Work, 61(4), pp. 421-428.

Swantz, M., Reason, P., \& Bradbury, H. (2008). 'Participatory action research as practice', in Reason, P. and Bradbury, H. (eds), The SAGE Handbook of Action Research, Thousand Oaks, CA, SAGE Publications Limited.

Thomas, D. (2006). A general inductive approach for analyzing qualitative evaluation data. American Journal of Evaluation, 27(2). pp. 237-246.

Watling, S., \& Rogers, J. (2012). Social work in a digital society. Exeter, UK: Learning Matters.

Waycott, J., Morgans, A., Pedell, S., Ozanne, E., Vetere, F., Kulik, L., \& Davis, H. (2015). Ethics in Evaluating a Sociotechnical Intervention With Socially Isolated Older Adults. Qualitative Health Research. http://doi.org/10.1177/1049732315570136

Waycott, J., Pedell, S., Vetere, F., Ozanne, E., Kulik, L., Gruner, A., \& Downs, J. (2012). Actively engaging older adults in the development and evaluation of tablet technology. In Proceedings of the 24th Australian Computer-Human Interaction Conference (pp. 643-652). Retrieved from http://dl.acm.org/citation.cfm?id=2414633

Waycott, J., Vetere, F., \& Pedell, S. (2013). Designing communication technologies for socially isolated older people: Fieldwork reflections. Paper Presented at the CHI 2013 Workshop on Designing for - and with - Vulnerable People.

West, D., \& Heath, D. (2011). Theoretical pathways to the future: Globalization, ICT and social work theory and practice. Journal of Social Work, 11(2), pp. 209-221. 